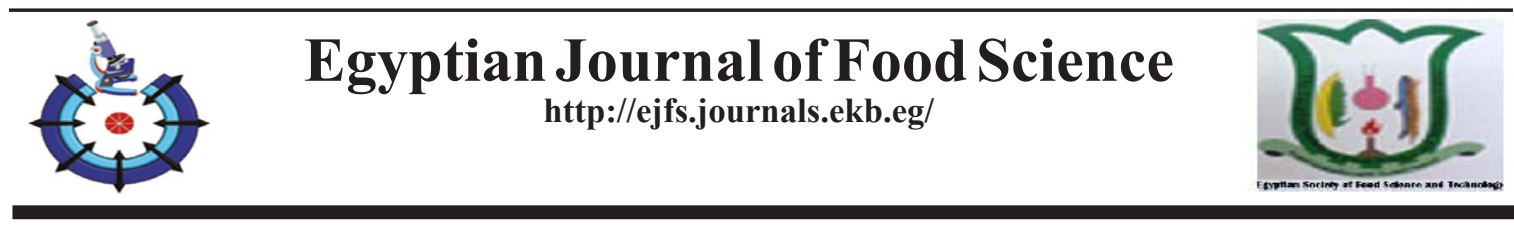

\title{
Optimization of Production of Monascus Ruber Pigments on Broth Medium and Their Application in Flavored Yogurts
}

\author{
Hossam E. F. Abdel-Raheam ${ }^{1}$, Wael S. Abdel-Mageed ${ }^{2}$ and Mokhless A. M. Abd \\ El-Rahman $^{3}$ \\ ${ }^{1}$ Food Science Department, Beni-suef Univ., Beni-suef, Egypt \\ ${ }^{2}$ Genetics Department, Beni-suef Univ., Beni-suef, Egypt \\ ${ }^{3}$ Food Sciences \& Technology Dept. Fac. of Agric. Assuit Univ. Egypt
}

\begin{abstract}
$\mathbf{T}$ THE AIM of the present study was to optimize production conditions of yellow, orange and red pigments from the fungus Monascus ruber Went AUMC 5705 culture through submerged fermentation (SMF), then separation and application of the produced pigments individually in flavored yogurts. Maximum pigments productivity was achieved at incubation temperature of $30^{\circ}$, inoculumssize by $4 \%(\mathrm{~V} / \mathrm{V})$ with $\left(36 \times 10^{4}\right.$ spores $/ \mathrm{ml}$ of inoculum), $\mathrm{pH}$ of 6.5 and incubation period of 11 days. The favorable carbon and nitrogen sources were Dextrin and monosodium glutamate at $4 \%(\mathrm{~W} / \mathrm{V})$ and $1.5 \%(\mathrm{~W} / \mathrm{V})$ concentrations respect. The present study has also revealed that the yogurt preparations supplemented with these pigments received highly acceptability. To the best of our knowledge, this is the first report on application of yellow, orange and red Monascus pigments individually in flavored yogurts. It is fervently hoped that in the future, these fungal pigments could receive greater attention in the field of food industries.
\end{abstract}

Keywords: Monascus ruber Went AUMC 5705, Pigments, Flavored yogurts, SMF, Food.

\section{Introduction}

Researches on Monascus pigments (MPs) include methods used for the isolation and identification of new pigments and application invaryingobjects especially in food industries has been very rapidly progressed. Application of the natural MPs to some foodstuffs with the aim to improve their quality, durability, storage, nutritious value and visual attraction also promotes positive health aspects of these foods (Mal'a et al., 2010).

Monascus represents a genus of small, filamentous, saprophytic fungi, belonging to Eumycophyta, Ascomycotina, Plectomycetes, Eurotiales, Monascaceae (Yang et al., 2016). Monascus strains are a source of various secondary bioactive metabolites including pigment (Patakova et al., 2015). Monascus pigments (MPs) contain six main compositions, namely, two yellow pigments (ankaflavin and monascin), two orange pigments (monascorubin and rubropunctatin) and two red pigments (monascorubramine and rubropunctamine) (Patakova, 2013).

MPs have long been used as natural food colorants, in South China. They are also used for production of red yeast rice, which is rice fermented by a red Monascus species which can be used to dye yoghurt, bacon, sausage, and for the preservative of fruits, vegetables, and fish products (Singgih and Julianti, 2015).

MPs have been used as a functional food additive for several thousands of years. Modern research found that MPs have many applications such as coloring agents in foodstuffs and texture industries, pharmacology, medicine and cosmetics (Mostafa and Abbady, 2014). Moreover, MPs possessed a range of biological activities, such

${ }^{*}$ Corresponding author : drmokhless@gmail.com

Received :16/11/2019; accepted : 23/12/2019

DOI: $10.21608 /$ EJFS.2019.19654.1030

(C)2019 National Information and Documentation Centre (NIDOC) 
as antimutagenic and anticancer properties (Hsu et al., 2011), antidiabetic effects (Shi and Pan, 2011 and Lee et al., 2011) antimicrobial activities (Martlnková et al., 1995; Kim et al., 2006 and Vedruscolo et al., 2015), potential anti-obesity characteristics (Feng et al., 2012), and antioxidant (Tseng et al., 2006; Yang et al., 2006 and Pyo \& Lee, 2007).

According to literature, substantial effort has been made to evaluate factors that effect of MPs production, such as $\mathrm{pH}$, temperature, incubation period, dissolved oxygen, and nutritional requirements such as carbon and nitrogen sources to cultivate and to use this information to optimize the culture conditions on both submerged and solid state fermentation (Zeng et al., 2018).

The present work, deals with optimization of physical and nutritional conditions in the pigments production from Monascus ruber Went AUMC 5705 by using submerged culture, separation of red, orange and yellow Monascus pigments from optimized culture and application of the separated pigments individually in flavored yogurt were also main aims.

\section{Materials and Methods}

\section{Culture}

Non mycotoxinproducer culture of Monascus ruber Went AUMC 5705 obtained from Assuit University Mycological center (AUMC), Assuit, Egypt, was used in the present study. The fungal culture was maintained on Yeast Extract-PeptoneDextrose agar (YEPD) medium, at $4^{\circ} \mathrm{C}$ and subculture speriod every three weeks, as described by Verma et al. (2000).

\section{Inoculum preparation}

M. rubber Went AUMC 5705 was grown on YEPD slant agar in the dark at $30^{\circ} \mathrm{C}$ under static conditions. To fullys porulated (6-8 days old) agar slope culture, $10 \mathrm{mlof}$ sterile distilled water was added and the spores were scrappe dunder strict aseptic conditions. The sporesuspension obtained was used asinoculum (approximately $36 \times 10^{4}$ spores perml) as described by Babitha et al. (2007b)

\section{Fermentation medium}

The fermentation medium consisted of glucose, $20 \mathrm{~g}$; monosodium glutamate, $5 \mathrm{~g} ; \mathrm{K}_{2} \mathrm{HPO}_{4}, 5 \mathrm{~g}$, $\mathrm{KH}_{2} \mathrm{PO}_{4}, 5 \mathrm{~g}, \mathrm{CaCl}_{2}, 0.1 \mathrm{~g}, \mathrm{MgSO}_{4} .7 \mathrm{H}_{2} \mathrm{O} 0.5 \mathrm{~g}$, $\mathrm{FeSO}_{4} .7 \mathrm{H}_{2} \mathrm{O} 0.01 \mathrm{~g}, \mathrm{ZnSO}_{4} .7 \mathrm{H}_{2} \mathrm{O} 0.01 \mathrm{~g}, \mathrm{MnSO}_{4}$. $\mathrm{H}_{2} \mathrm{O} 0.03 \mathrm{~g}$ and $1000 \mathrm{ml}$ of distilled water. One hundred milliliters of broth of this fermentation medium were dispensed into a $500 \mathrm{ml}$ Erlenmeyer flask, adjusted to $\mathrm{pH} 6.5$ and autoclaved at $121^{\circ} \mathrm{C}$ for $15 \mathrm{~min}$. After cooling, the medium was inoculated with $1 \mathrm{ml}$ spore suspension $\left(36 \times 10^{4}\right.$ spores $\left./ \mathrm{ml}\right)$ and incubated at $30^{\circ} \mathrm{C}$ for 7 days under static condition (Ahmad et al., 2009).

Determination of optimized conditions for pigments production

For optimization of fermentation temperature the pigments broth production media which inoculated with the selected organism were incubated at temperatures Viz. 20, 25, 30, 35 and $40^{\circ} \mathrm{C}\left( \pm 1^{\circ} \mathrm{C}\right)$ for one week. To check the effect ofinoculumsize on the yield of red, orange and yellow pigments fungus strain was inoculated in thepigmentbroth production medium with differentsporesuspension concentrations $(1.0 \%$, $2.0 \%, 3.0 \%, 4 \%$ and $5 \% \mathrm{~V} / \mathrm{V}$ ) and incubated for one week at the optimum temperature known from the previous experiment.For optimization of the $\mathrm{pH}$, fungus strain was inoculated at the optimum inoculum size in broth media adjusted to different $\mathrm{pH}$ values (viz. 4.5, 5.5, 6.5, 7.5 and 8.5 ) and incubated at the optimum temperature for one week.

For optimization of incubation time the organism was incubated for different time interval viz. 5, 7, 9, 11, 13, 15, 17 and 19 days at the optimum conditions obtained from the previous experiments. Experiments were also performed to evaluatethe effectof addition of different carbon sources such as glucose, sucrose, maltose, lactose, dextrin and soluble starch at $1.0 \%$ concentration of each.For optimization of incubation time the organism was incubated for different time interval viz. 5, 7, 9, 11, 13, 15, 17 and 19 days at the optimum conditions obtained from the previous experiments. Experiments were also performed to evaluatethe effectof addition of different carbon sources such as glucose, sucrose, maltose, lactose, dextrin and soluble starch at $1.0 \%$ concentration of each.

Experiments were also performed to evaluate the influence of the addition of different organic and inorganic nitrogen sources such as monosodium glutamate, peptone, yeast extract, beef extract, ammonium nitrate, ammoniumsulfate, ammonium chloride, potassium nitrate and urea at $1.0 \%$ concentration of each. The optimum concentration of the selected nitrogen source (monosodium glutamate) which stimulatespigmentproduction was estimated by adding it at different concentrations $(1.0,1.5,2.0$, 2.5 and $3.0 \%$ ) to the production medium.All the experiments were carried out in triplicates and mean yield was calculated for each observation.

\section{Pigment extraction and quantification}

At the end of the incubation periodof each experiment, the contents of each flask were filtered using Whatman No. 1 filter paper and washed with distilled water. The washedmycelia

Egypt. J. Food. 47, No. 2 (2019) 
were kept aside for measuring the intracellular pigment. The filtrate was measured by a UV visible spectrophotometer (Abilene 9400 - SCHOTT Instruments, EU) at 400, 470, and $500 \mathrm{~nm}$ for yellow, orange, and red pigments, respectively (Carels and Shepherd, 1977; Lin et al., 1992 and Orozco and Kilikian, 2008). If necessary, the filtrate was further diluted with distilled water to ensure that the absorbance reading was in the range between $(0.3 \sim 0.7)$. The un-inoculated medium was used as blank.

For measuring the intracellular pigment, the freshly harvested washed mycelia $(0.1 \mathrm{~g})$ were transferred to a $50 \mathrm{~mL}$ Erlenmeyer flask and 10 $\mathrm{mL}$ of ethanol $95 \%$ was added. The suspension was allowed to stand at $30^{\circ} \mathrm{C}$ for $12 \mathrm{hr}$ (Lin \& Demain, 1991 and Tseng et al., 2000). The supernatant was then recovered by centrifugation (using Himac CR 22GII, Hitachi Koki Company Limited, Japan) at $10000 \mathrm{~g}$, for $10 \mathrm{~min}$. The absorbance of the clear solution was measured at 500, 470, and $400 \mathrm{~nm}$ using a UV visible spectrophotometer to determine red, orange, and yellow pigments, respectively (Chen \& Johns, 1993; Lin \& Iizuka, 1982 and Lin \& Demain, 1991). If necessary, the supernatant was diluted with ethanol $95 \%$ to ensure that the absorbance reading was in the range between $(0.3 \sim 0.7)$.

Extra and Intracellular Pigments yield in absorbance unit (AU) / $\mathrm{ml}$ were calculated by using following formula (Mekhael and Yousif, 2009):

$$
\begin{gathered}
\mathrm{AU}=\mathrm{AU} \mathrm{Total}_{\text {extra }}+\mathrm{AU} \mathrm{Total} \mathrm{intra} \\
\text { Which: } \mathrm{AU}_{\text {Total extra }}=\mathrm{AU} \mathrm{extra} \times \mathrm{df} \\
\mathrm{AU}_{\text {Total intra }}=(\mathrm{AU} \text { intra } \times \mathrm{df}) /(\text { weight of sample }(\mathrm{g})) \\
\times \text { "total weight of biomass" }(\mathrm{g})
\end{gathered}
$$

Where, df is the dilution factor and AU is the total absorbance unit of extra and intracellular pigments.

\section{Separation of pigments}

The red, orange and yellow pigments were separated and purified individually from submerged culture, according to the procedures that described by Abdel-Raheam (2016). Separated water soluble red, orange and yellow pigments were used individually in the preparation of red, orange and yellow flavored yogurts.

Application of the separated pigments for the coloring of flavored yoghurts

Yoghurt was manufactured from Buffalos milk by the traditional methods and Red, orange and yellow pigments were added to yoghurts flavored with strawberry, orange and banana, respectively. Few drops of each concentrated pigment extract were added to give a color degree similar to that of the commercial corresponding products. All products were kept at $4^{\circ} \mathrm{C}$ for 3 days and then subjected to sensory evaluation. Attributes of color, taste, odor, texture and overall acceptability were tested using slandered score card.

\section{Sensory evaluation}

Sensory evaluation was carried out by ten panelists. The panelists were asked to evaluate taste, color, texture, odor and overall acceptability for prepared Red, orange and yellow flavoredyoghurts according to the method described by Reitmeier and Nonnecke (1991).

\section{Results and Discussion}

\section{Production of Monascus pigments}

As shown in Fig. 1 the use of submerged culture technique resulted in successful growth of the fungus Monascus ruber Went AUMC 5705 accompanied with successful production of fungal biomass and concentrated fungal pigments.

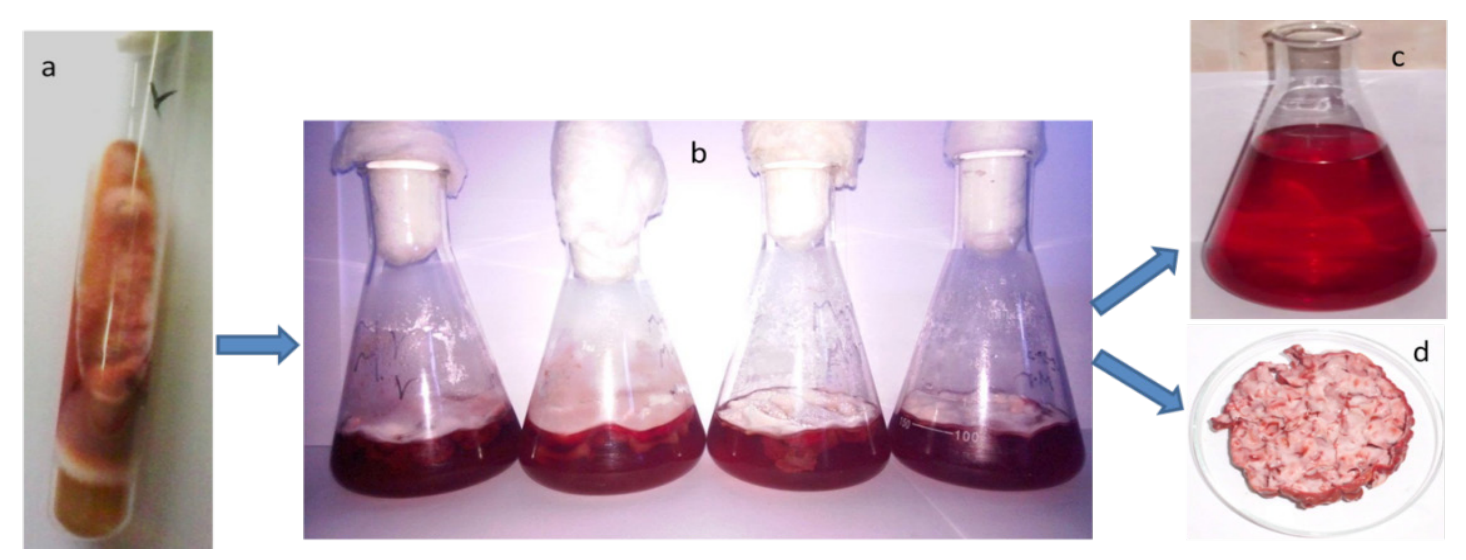

Fig. 1. Production of Monascus ruber Went AUMC 5705 pigments by submerged culture technique: (a) fungal slant, (b) Fermented broth culture, (c) Filtrated culture and (d) Separated biomass. 
Optimum incubation temperature

The results illustrated in Fig. 2 show that production of red, orange and yellow pigments were increased gradually with increasing the incubation temperature from 20 to $30{ }^{\circ} \mathrm{C}$ and then turned to gradually decrease with increasing the incubation temperature up to $30 \sim 40{ }^{\circ} \mathrm{C}$. So $30^{\circ} \mathrm{C}$ was considered as optimal temperature, which gave maximal red, orange and yellow pigments productivity from Monascus ruber Went AUMC 5705.

This finding agrees with the reports of Rashmi and Padmavathi (2013 and 2012); Padmavathi and Prabhudessai (2013); Sunet al. (2004); Park et al. (2005); Jeon et al. (2006) and Juzlova et al. (1996). These observations were closely consistent with previous investigators (Sumathy et al., 2007; Lin, 1991; Perth, 1985). Dikshit and Tallapragada (2011) also found that, the pigment amount decreases at $37^{\circ} \mathrm{C}$ and a drastic reduction in red pigment beyond $40{ }^{\circ} \mathrm{C}$ was reported by Babitha (2007a). Hence, temperature plays a pivotal role in cell metabolism, thusinfluencing pigment yield.On the other hand, Minoru et al., (1975) found that, the optimal temperature for red pigment production by Monascus sp. No.2 (AJ7744) fungus strain was $25{ }^{\circ} \mathrm{C}$, and at the temperature lower than $25^{\circ} \mathrm{C}$ and higher than $28^{\circ} \mathrm{C}$, markedly decrease in pigment production was observed.

\section{Optimum inoculum size}

The results in Fig. 3 show that, Production of red, orange and yellow pigments were increased as the inoculumsize increased from up to $4 \%$. Therefore, $4 \%$ was selected as the best economicalinoculumsize for the tested fungus strain. Ji et al. (2012) and Babitha et al. (2007a) mentioned that high inoculasizes may increase biomass, but decreases pigment production, the inhibition of pigment formation was due to the lack of some substances in culture medium which were consumed by the high bacterial biomass. Santos-Ebinuma et al. (2013b) found that, the highest production of yellow, orange, and red colorants was achieved with $4 \times 10^{8}$ (spores/ $\mathrm{ml} / 100 \mathrm{ml}$ medium while using submerged culture fermentation for production of pigments by Penicillium purpurogenum DPUA1275.

It is advantageous to achieve high levels of the product by smallinoculum size $14 \times 10^{5}$ spores/ $100 \mathrm{ml}$ broth medium as obtained from our results. This may reflect a high potentiality of the studied fungal strain.

\section{Optimum initial $\mathrm{pH}$ value}

It is well known that the initial $\mathrm{pH}$ of the medium, in which the organism is grown, has a great influence on enzymes and pigments production. Therefore, an experiment was designed to investigate the effect of different $\mathrm{pH}$ values on production of intra and extra cellularred, orange and yellow pigments by Monascus ruber Went AUMC 5705. The results illustrated in Fig. 4 indicated that the optimum $\mathrm{pH}$ for the production of red, orange and yellow pigments was 6.5 for the tested fungus strain. The change of the $\mathrm{pH}$ value above or below 6.5 resulted in decreasing the production of intra and extracellular red, orange and yellow pigments.

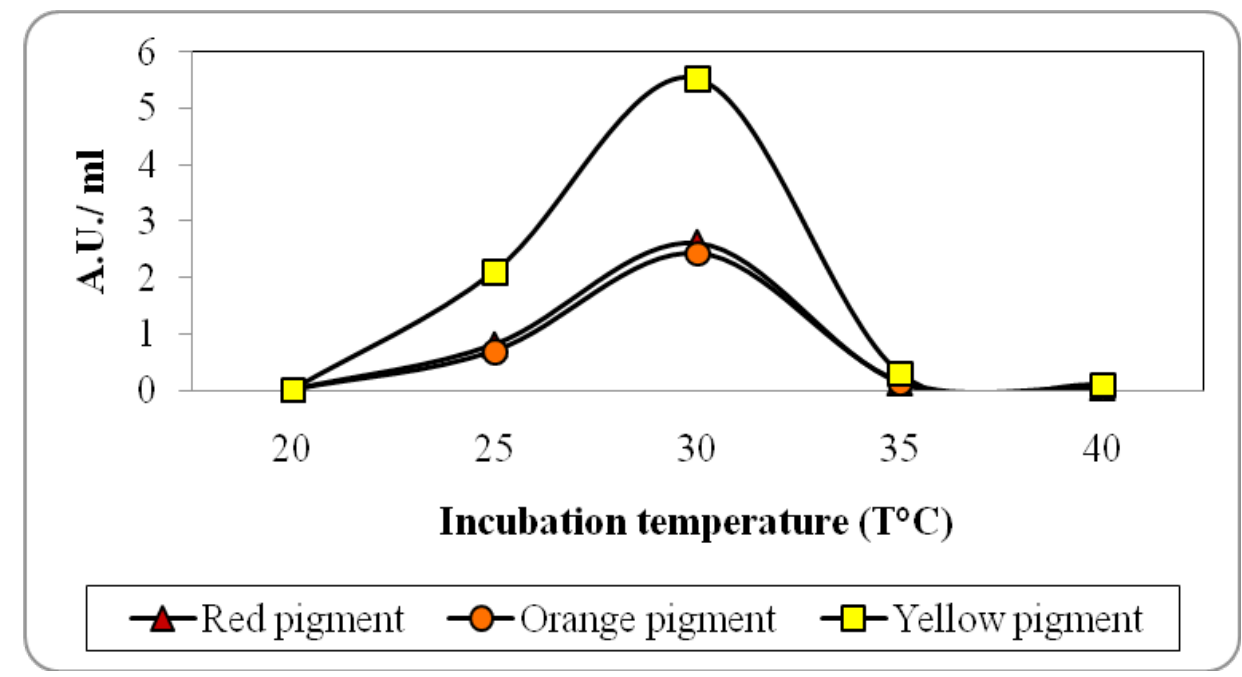

Fig. 2. Effect of incubation temperature on red, orange and yellow pigments production by submerged culture of M. ruber Went AUMC 5705.

Egypt. J. Food. 47, No. 2 (2019) 


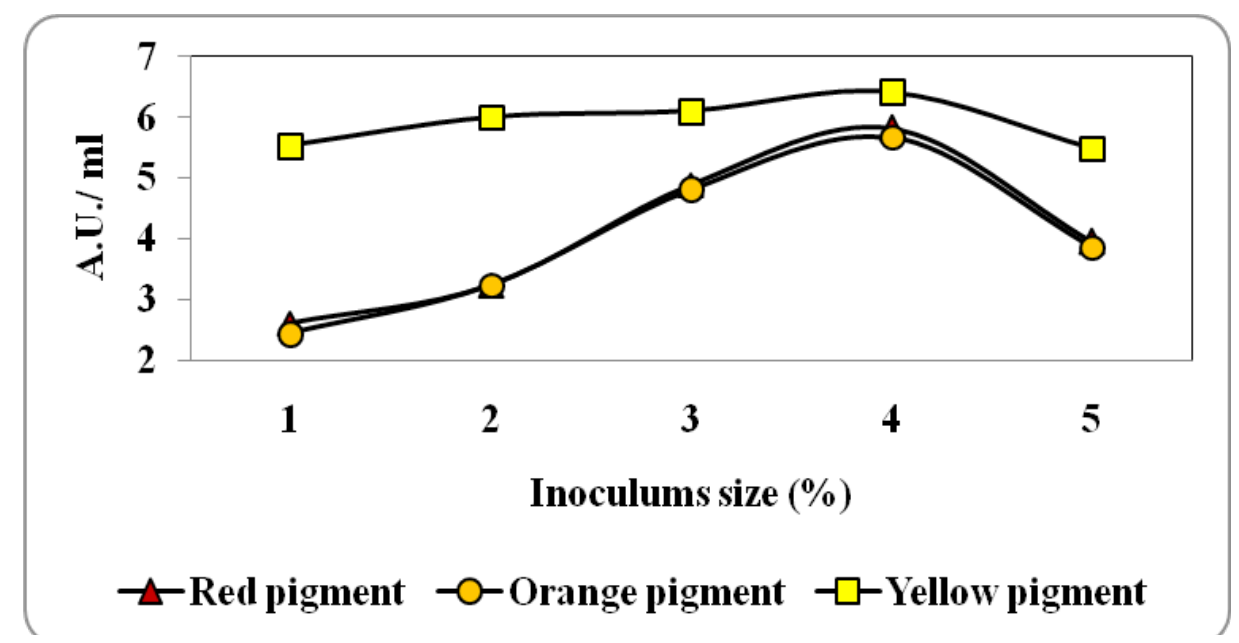

Fig. 3. Effect of inoculum size (\%) on red, orange and yellow pigments production by submerged culture of M. ruber Went AUMC 5705.

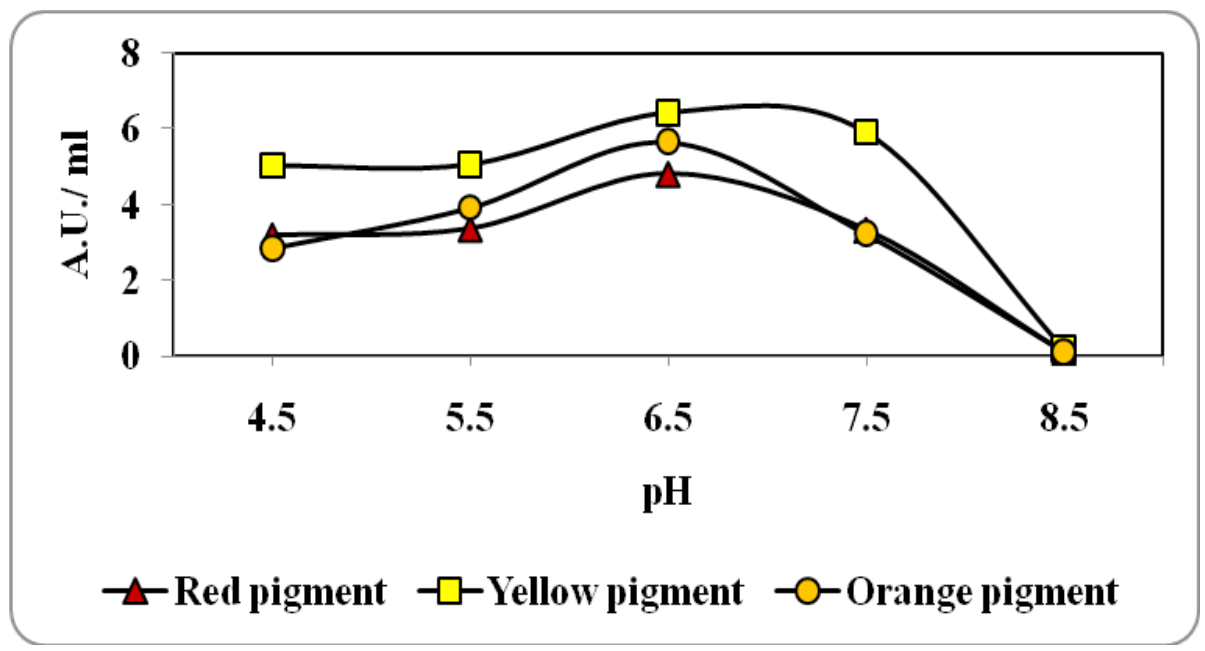

Fig. 4. Effect of initial pH on red, orange and yellow pigments production by submerged culture of M. ruber Went AUMC 5705.

These results agree with those obtained by Rashmi and Padmavathi (2013); Jeon et al. (2006); Suh et al. (2004) and Minoru et al. (1975)).

However, the present results have rather differed from those described by Park et al. (2005) and Rashmi \& Padmavathi (2012) who found that pigment production by $M$. purpureus MTCC410 and $M$. purpureus $\mathrm{P}-57$ were highest in a medium with an initial $\mathrm{pH}$ of 5.5 and 5.0, respectively.

\section{Optimum incubation period}

In industrial fermentation, it is of great economic importance to harvest the product in short time. Therefore, an experiment was conducted to investigate the rate of the pigment production during different fermentation periods and to determine the suitable time at which the product could be maximized.
Data illustrated by Fig. 5 showed that the rate of pigment production increased gradually as the incubation period increased, reaching the maximum value after 11 days, and then dropped until it reached the minimum value after 19 days for the tested fungal strain.

The present results are rather different from those described by Rashmi and Padmavathi (2013) who reported that maximum pigment production were achieved by Monascus sanguines with in 16 days, while using MGPB(malt glucosepeptone broth) and PDB (potato dextrose broth) in submerged fermentation. SantosEbinuma et al., (2013b) found that, the highest colorants (yellow, orange, and red) production by Monascus purpureus MTCC 410 and Penicillium purpurogenum DPUA1275 was achieved with 
in 14 days and 12 days of incubation time, respectively.On the other hand Chatterjee et al., (2009) reported that, the yield of pigment production reached to its highest level at $10^{\text {th }}$ day while using submerged culture fermentation for production of pigments by Monascus purpureus MTCC 1090.

Selection of the most efficient carbon sources

The results given in Fig. 6 indicated that dextrin was the best carbon source for red, orange and yellow pigment production followed by glucose for the studied fungus strain.

These results agree with those obtained by Joshi et al. (2003) who found that, the volum etricpigment formation by Monascus $s p$. Isbest on starch and dextrin, moderate on glucose and maltose but poor on fructose. They also reported that, maltose and glucose as carbon sources gave very dark liver pigment by M. Purpureus, where as sucrose produceda lightand uneven red pigment. Also, Lin and Demain (1991) reported that, glucose and its oligo- and polysaccharides were better carbohydrates than maltose and fructose for both growth and MPs production of Monascus sp. TTWMB 6042.

These results agree with those obtained by Lee et al. (1995) who investigated Complex carbon sources such as starch for possible use in producing Monascus pigments in submerged culture. They found that the viscosity of starch solution was leading to the poor oxygen transfer, consequently, low biomass and pigments production.

Glucose was held by most authors (Chatterjee et al. (2009); Juzlova et al. (1994); Lin and Demain (1991); Panitz et al. (1991); Broder and Koehler (1980) and Yoshimura et al. (1975)) to be a superior substrate for pigment production by Monascus species. However, others (Miyake et al., 1982) found glucose to be less suitable for this purpose. This may be caused by strain differences or by other differences in medium composition (glucose concentration, type of nitrogen source).

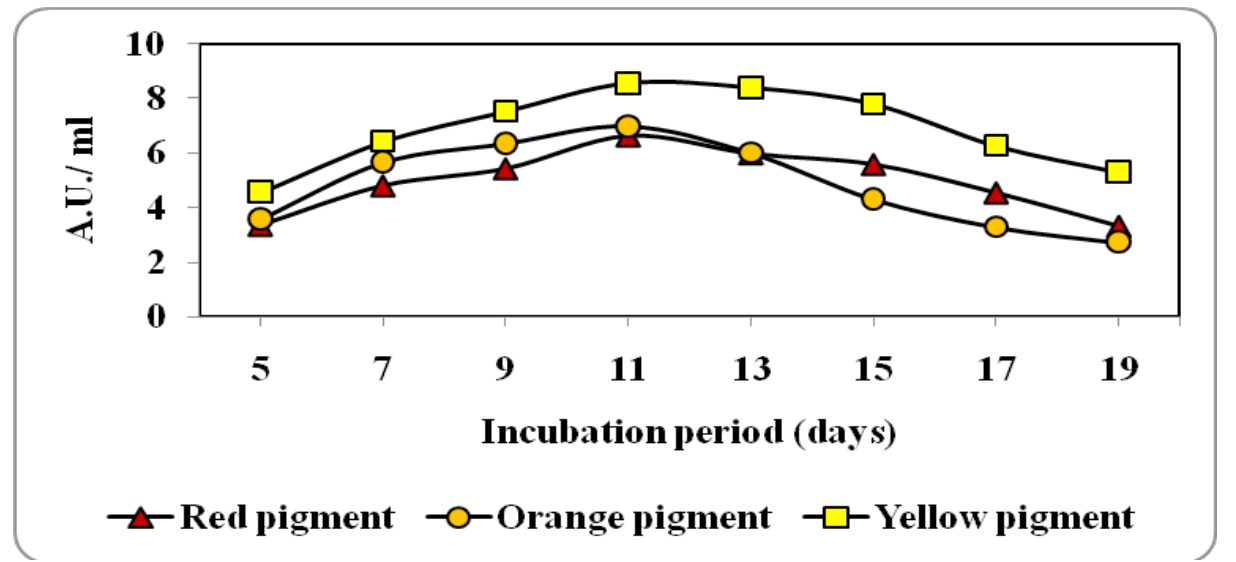

Fig. 5. Effect of incubation time (days) on red, orange and yellow pigments production by submerged culture of M. ruber Went AUMC 5705.

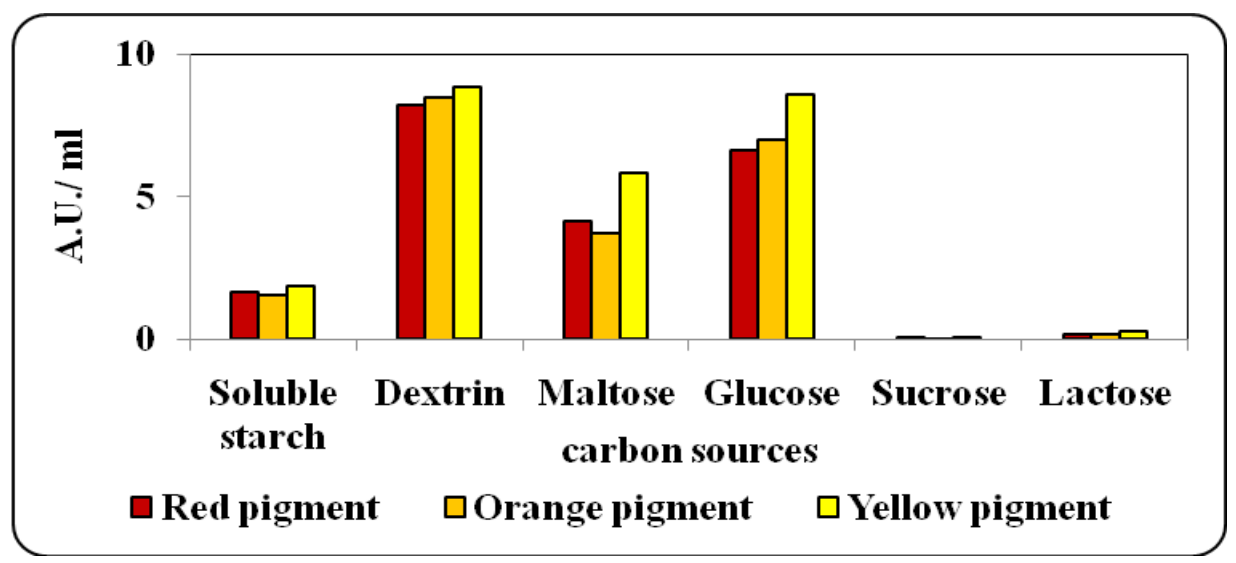

Fig. 6. Effect of carbon sources on red, orange and yellow pigments production by submerged culture of M. ruber Went AUMC 5705.

Egypt. J. Food. 47, No. 2 (2019) 


\section{Optimum Dextrin concentrations}

From the previous experiment, dextrinsecured maximum yield of red, orange and yellow pigments when used as a sole carbon source for the studied fungus strain. Therefore, an experiment was carried out to study the effect of different concentrations of destroying that could stimulate the highest pigment production. Results recorded in Fig. 7 clearly showed that, the accumulation of red, orange and yellow pigments were increased gradually as the destroyingconcentration increased, reachingthe maximum level at $4 \%$ concentration for the tested fungus strain (data not shown).

\section{Selection of the most efficient nitrogen sources}

This experiment was aimed to investigate the best nitrogen source that could stimulate maximum pigment production by Monascus ruber Went AUMC 5705. Data represented by Figure 8 indicated that monosodium glutamate (MSG) was the most favorable nitrogen source for the stimulation of red, orange and yellow pigment production by the studied fungus strain. These results were consistent with the published reports for other Monascus strains by Babitha et al. (2007a); Carvalho et al. (2005) and Chatterjee et al. (2009). These workers reported that MSG proved to be the best nitrogen source for producing the red pigment in submerged culture. Also they reported that, the nitrogen sources that contained $\mathrm{NH}_{4}^{+}$proved to be quite unsatisfactory for development of the red pigment.

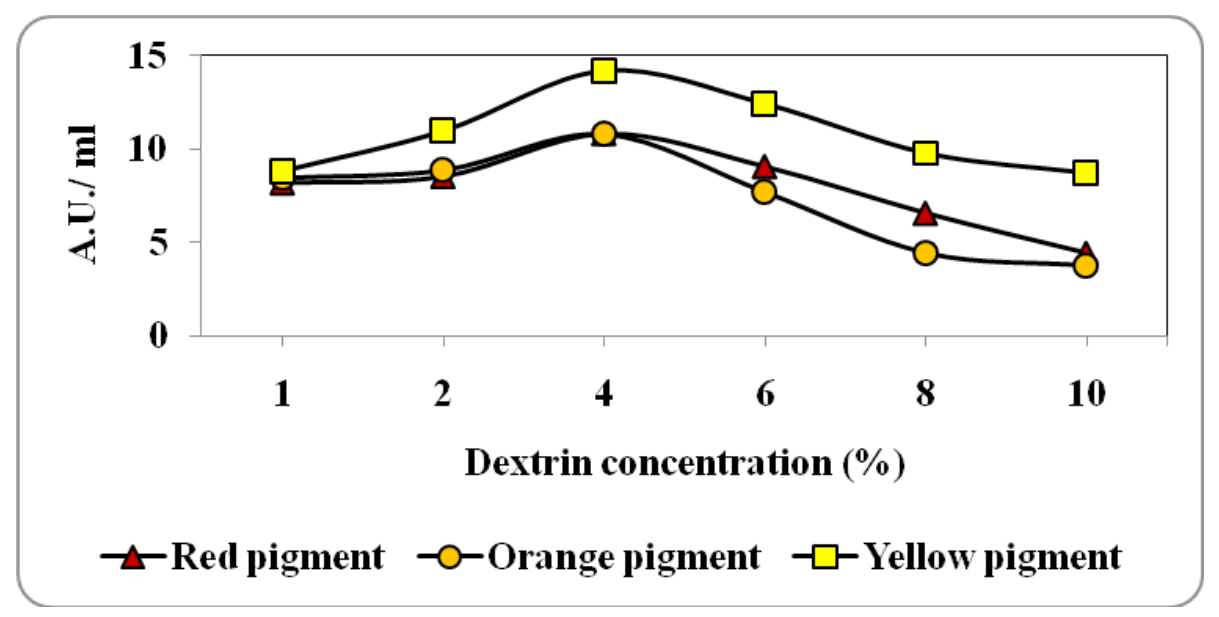

Fig. 7. Effect of Dextrin concentration (\%) on red, orange and yellow pigments production by submerged culture of M. ruber Went AUMC 5705.

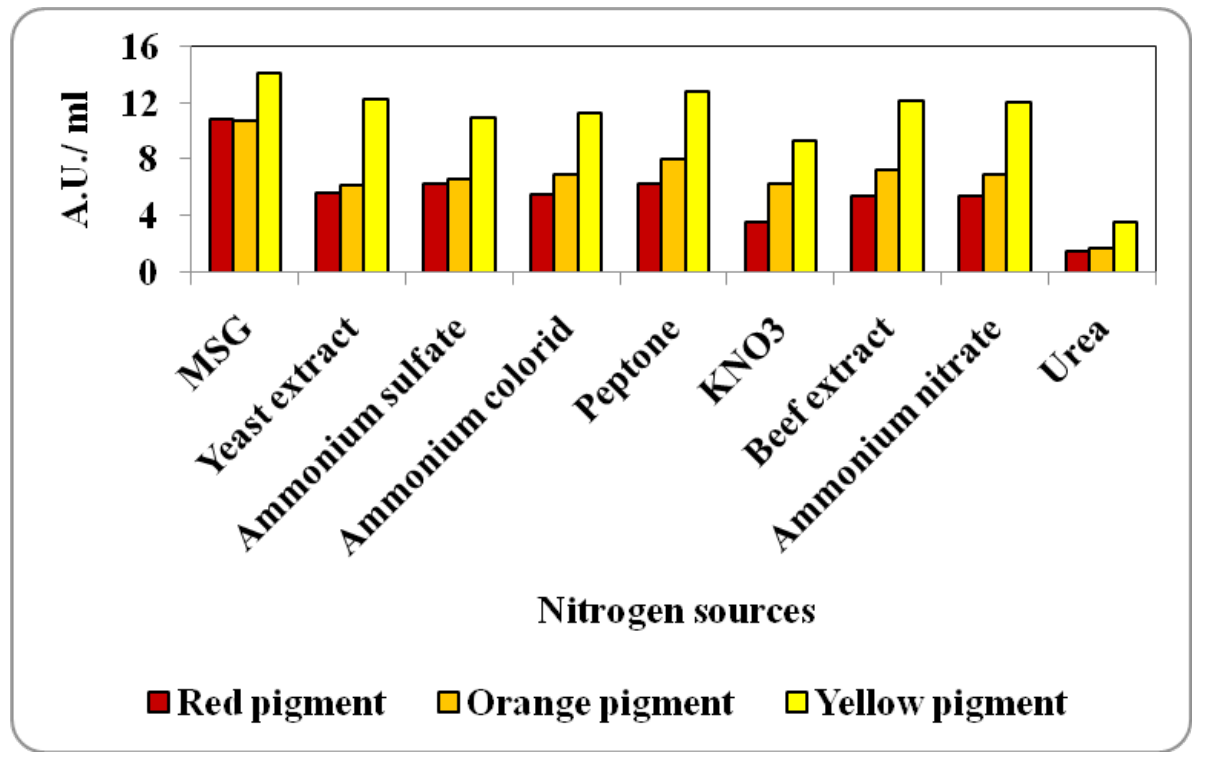

Fig. 8. Effect of nitrogen sources on red, orange and yellow pigments production by submerged culture M. ruber Went AUMC 5705. 
Chen and Johns(1993) reported that ammonium chloride, peptone also yielded superior growth and pigment amounts by $\mathrm{M}$. purpureus UQM 192F (FRR 2190) when compared with sodium nitrate. These results agree with those obtained with Chatterjee et al. (2009) who observed that maximum red pigment yield by Monascus purpureus MTCC 1090 was observed when the production broth medium was supplemented with $0.3 \%$ monosodium glutamate (MSG). Also, Lee et al. (2001) found that maximum red pigment yield by Monascus purpureus (ATCC 16365) was observed when the production broth medium was supplemented with (1.5g/L) $0.15 \%$ MSG.

\section{Optimum MSG concentration}

The results illustrated in Fig. 9 showed that the optimum concentration of MSG that secured the highest pigment production were $1.5 \%$ for the studied fungus strain. These results agree with those obtained by Joshi et al. (2003) who reported that in Monascus purpureus, $1.5 \%$ MSG medium produced an appealing red colour, whereas other nitrogen sources produced faint or foggy red pigment.
The present results have rather differed from those described by Lee et al., (2001) who found that, maximum red pigment yield by Monascus purpureus (ATCC 16365) was observed whenthe production broth medium was supplemented with $(1.5 \mathrm{~g} / \mathrm{L}) 0.15 \% \mathrm{MSG}$. While, Chatterjee et al., (2009) observed that, maximum red pigment yield by Monascus purpureus MTCC 1090 was observed when the production broth medium was supplemented with $0.3 \% \mathrm{MSG}$ in liquid fermentation.

Qualitative analysis of the mycotoxin, citrinin

Studies were carried out to identify the presence of Citrinin toxin in the submerged fermented culture by Monascus ruber Went AUMC 5705 using thin-layer chromatography (TLC). As shown in Fig. 10 TLC analysis showed that no Citrinin was detected in submerged culture extract. Hence the Monascus ruber Went AUMC 5705 used in this study was found to be safe for food use.

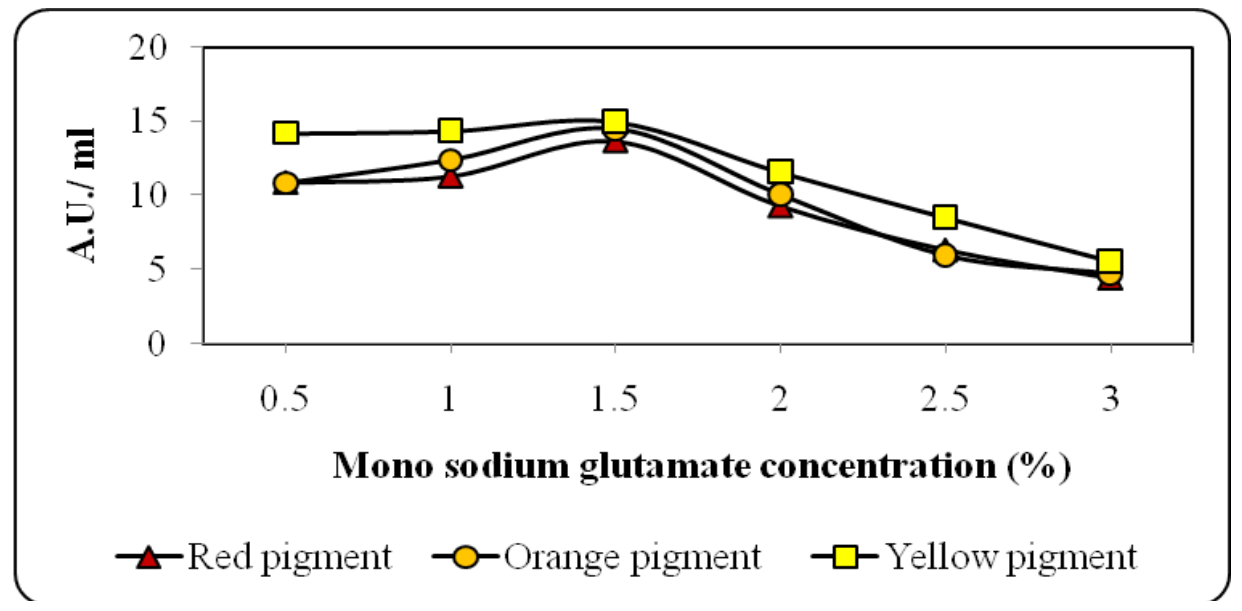

Fig. 9. Effect of MSG concentration (\%) on red, orange and yellow pigments production by M. ruber Went AUMC 5705.

Fig. 10. Detection of Citrinin by TLC under UV detector on extract of submerged culture.

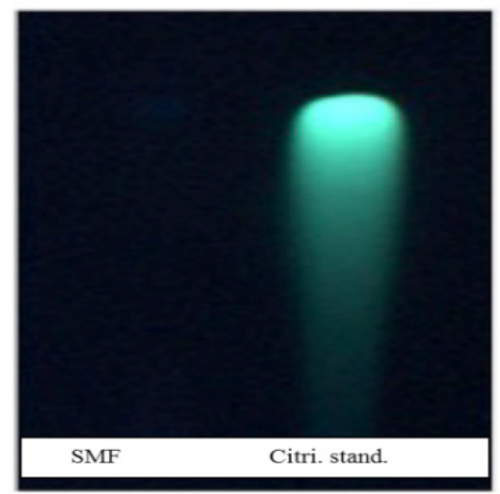

Egypt. J. Food. 47, No. 2 (2019) 


\section{Separation of the produced pigments}

The method used for pigments separation successfully resulted in fractionation of the crude Monascus pigments into three individual colors, red, orange and yellow ready to use as food colorants (Fig. 11).

Sensory evaluations of the produced pigmentsas colorant additives for yogurts

Concentrated pigments which extracted and separated from submerged Monascus ruber Went AUMC 5705 culture were utilized as colorant additives for yogurts to enhance its appearance and acceptability. The red, orange and yellow flavored yogurts were developed by adding the separated Monascus pigments individually. In the current study, $M$. ruber pigments directly mixed with the food products during their preparation (as described by Abdel-Raheam, (2016)) to impart red, orange and yellow pigments individually to these products (Fig. 12) and improving the aesthetic value.

The prepared yogurts using Monascus pigments as colorants were sensory evaluated for taste, color, texture, odor and overall acceptability by ten panelists. Data in Table 1 shows the average sensory analysis scorecard and total scores for the separated M. ruber pigments as natural colors for the butterscotch flavoredyogurts. The overall average score for the red, orange and yellow flavored yogurts samples were $48.8,46.5$ and 46.4 , respectively.

In general, all prepared food product samples colored with Monascus ruber Went AUMC 5705 pigments were recorded highly scores in all sensory evaluated tested parameters as shown in Table 1. The average score for taste, color, texture, odor and overallacceptability were between 8.9 to 9.9 scored to be as 'like extremely' for all tested food products samples as described by Wang and Zhao (2008). The result shows that the incorporation of Monascus ruber Went AUMC 5705 pigments for coloring prepared food product has proved to be excellent. The pigment distributed evenly in the food product giving a pleasing appearance.

These results were similar to that reported by previous investigators such as Blanc et al., (1995) who reported that, food products gain more intense and stable red color and improved organoleptic characteristics when Monascus purpureus pigment was used. Moreover, application of the natural pigment promotes consumers health protection by decreasing the intake of salt and allows manufacturing fully natural food without any synthetic additives (Su et al., 2005). Traditionally, red rice, red wine, sausages, fish sauces, meat products, soybean curd were prepared with these pigments (Anonymous, 1999).

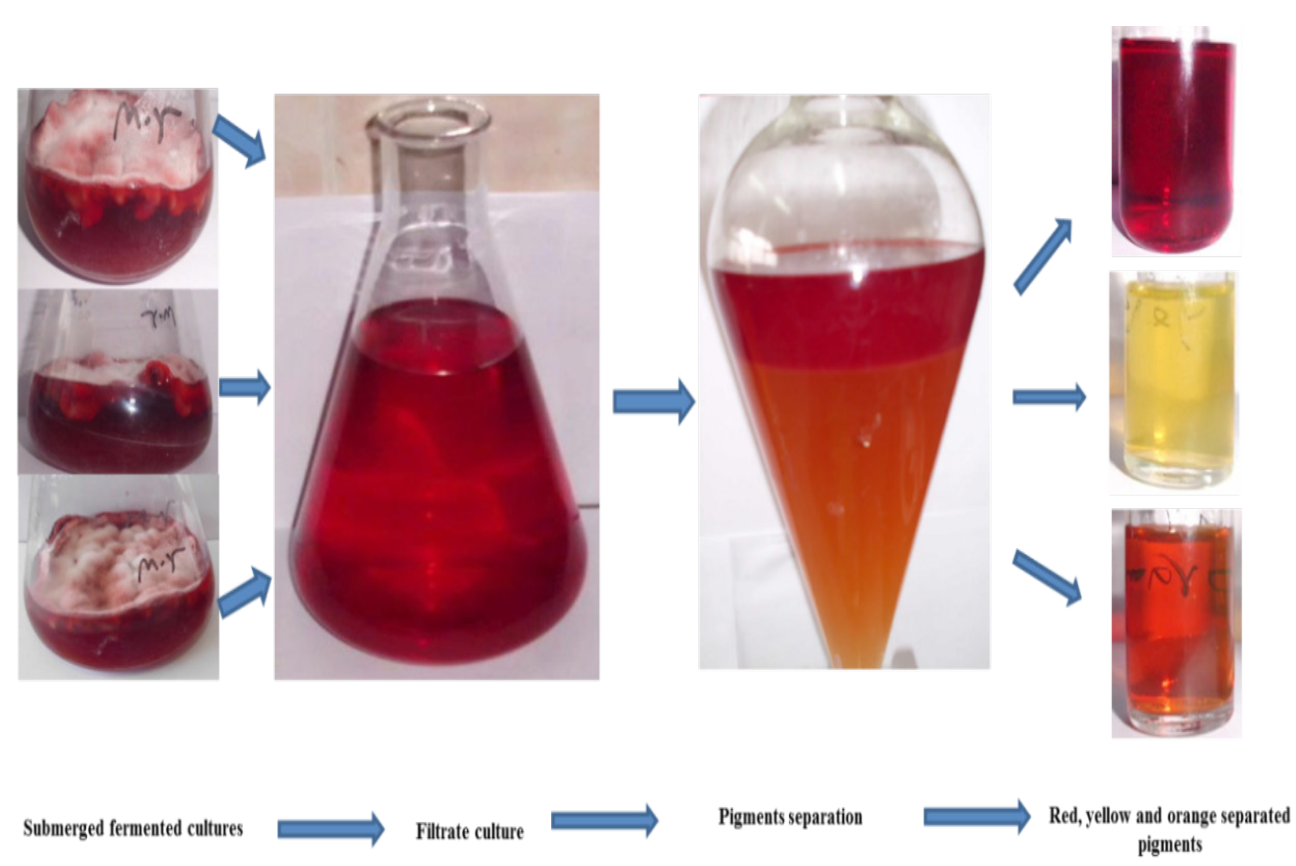

Fig. 11. Separation of Monascus ruber Went AUMC 5705 pigments from submerged fermented culture. 
TABLE 1. Mean sensory scores of food products samples coloured with Monascus ruber Went AUMC 5705 pigments.

\begin{tabular}{ccccccc}
\hline $\begin{array}{c}\text { Total score } \\
\mathbf{5 0}\end{array}$ & $\begin{array}{c}\text { Overall } \\
\text { Acceptability (10) }\end{array}$ & $\begin{array}{c}\text { Texture } \\
\mathbf{1 0}\end{array}$ & $\begin{array}{c}\text { Odour } \\
\mathbf{1 0}\end{array}$ & $\begin{array}{c}\text { Colour } \\
\mathbf{1 0}\end{array}$ & Taste 10 & Name of product \\
\hline $\mathbf{4 8 . 8}$ & 9.9 & 9.7 & 9.4 & 9.9 & 9.9 & Red yogurt \\
$\mathbf{4 6 . 5}$ & 9.2 & 9.1 & 9.5 & 9.0 & 9.7 & Orange yogurt \\
$\mathbf{4 6 . 4}$ & 9.1 & 9.6 & 9.3 & 8.9 & 9.5 & Yellow yogurt \\
\hline
\end{tabular}
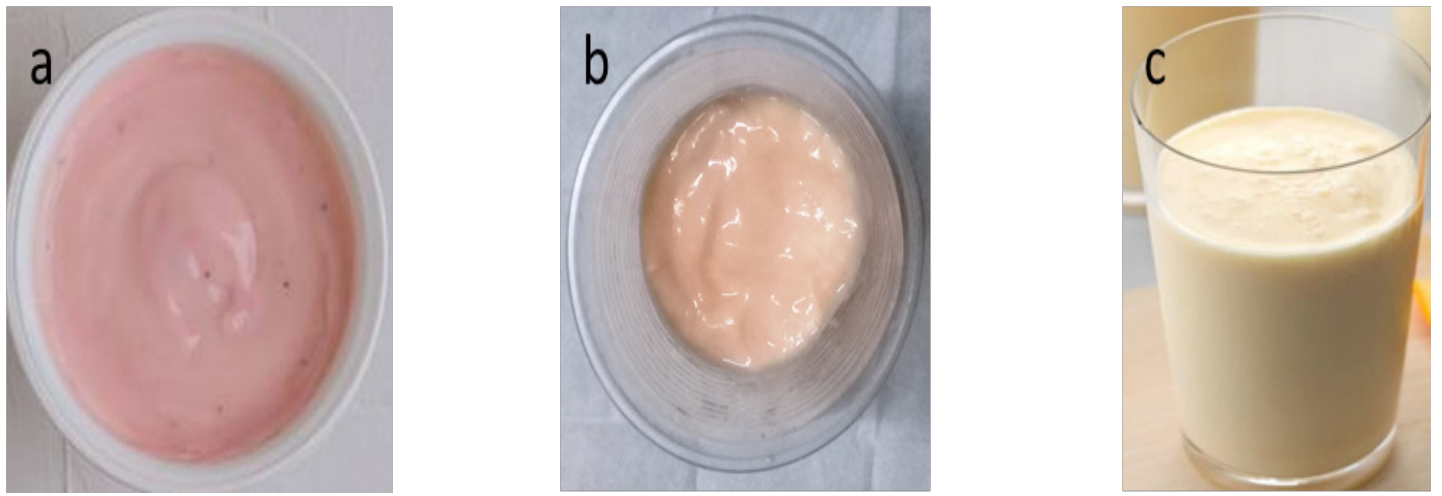

Fig. 12. Red (a), orange (b) and yellow (c) yogurts prepared by separated Monascus pigments.

Also, Vidyalakshmi et al. (2009) reported that Monascus ruber fermented rice (MFR) used as colorants in the preparation offood products (Kesari), and showed very goodcolorand appearance. They also studiedthe incorporationof MFR for coloring flavored milk, which showed that pigment distributed evenly giving an appealing color and pleasing appearance with better acceptability.

Also, this finding agrees with the reports of Mamucod and Dizon (2014); Pattanagul et al. (2007), Kraboun et al. (2009) and El-Kholie et al. (2012).

\section{Conclusion}

Considering the results of this study, the highest yield of yellow, orange and red pigments were $14.97,14.46$ and $13.65 \mathrm{AU} / \mathrm{ml}$, respectively, revealed that optimization of the environmental conditions has maximized Monascus ruber Went AUMC 5705 pigment production in 2.70, 5.94 and 5.23 times more than basal medium (5.53, 2.44 and 2.61 AU / ml) for yellow, orange and red, respectively in SMF. The produced pigments were applied as coloring agents for yogurt only (red, orange and yellow flavored yogurts). On the sensory evaluation, applications of this natural colorant in a preparation of these products were found to be highly acceptable.

Egypt. J. Food. 47, No. 2 (2019)

\section{References}

Abdel-Raheam, H. E. F. (2016) Production and evaluation of some natural food pigments from Monascus purpureus fungus. Ph.D. Thesis, Faculty of Agriculture, Assiut University, Egypt.

Ahmad, M. M., Nomani, M. S. and Panda, B.P. (2009) Screening of Nutrient Parameters for Red Pigment Production by Monascus purpureus MTCC 369 under Submerged Fermentation using Plackett Burman Design. Chia. Mai J. Sci., 36 (1), 104-109.

Anonymous, (1999) Doosan Training and Technology Centre. http://www.dst.doosan.com

Babitha, S., Soccol, C. R. and Pandey, A. (2007b) Solidstate fermentation for the production of Monascus pigments from jackfruit seed, Bioresour. Technol., 98, 1554-1560.

Babitha, S., Soccol, C.R. and Pandey, A. (2007a) Effect of stress on growth, pigment production and morphology of Monascus sp. in solid cultures. $J$. Bas. Microbial. 47, 118-126.

Blanc, P.J., Laussac, J.P., Le Bars, J., Le Bars, P., Bars Le, Loret, M.O., Pareilleux, A., Prome, D., Prome, J.C., Santerre, A.L. and Goma, G. (1995) Characterization of monascidin A from Monascus as citrinin. Int. J. Food Microbial. 27, 201-213. 
Broder, C.U. and Koehler, P.E. (1980) Pigments produced by Monascus purpureus with regard to quality and quantity. J. Food Sci., 45, 567-569.

Carels, M. and Shepherd, D. (1977) The effect of different nitrogen sources on pigment production and sporulation of Monascus species in submerged, shaken culture. Canad. J. Microbiol., 23, 13601372.

Carvalho, J.C.D., Oishi, B.O., Pandey, A. and Soccol, C.R. (2005) Biopigments from Monascus: Strains selection, citrinin production and color stability. Braz. Arch. Biol. Technol. Inter. J., 48, 885-894.

Chatterjee, S., Sharmistha, M., Chattopadhyay, P., Sarkar, A., Subrata, L. and Sen, S.K. (2009) Characterization of Red Pigment from Monascus in Submerged Culture Red Pigment from Monascus Purpureus, J. Appl. Sci. Res., 5 (12), 2102-2108.

Chen, M. H. and Johns, M. R. (1993) Effect of pH and nitrogen source on pigment production by Monascus purpureus. Appl. Microb. Biotechnol., 40, 132-138.

Dikshit, R. and Tallapragada, P. (2011) Monascus purpureus: A potential source for natural pigment production. Journal of Microbiology and Biotechnology Research, 1 (4), 164-174.

El-Kholie, E.L., El Shaer, M.K., Abdelreheem, M.A.T. and Gharib, M.A. (2012) Detailed evaluation of a newly attained fungal pigments from Monascus purpureus in meat burgers. Int. J. Food Sci. Nutr., 63 (7), 860-5.

Feng, Y., Shao, Y. and Chen, F. (2012) Monascus pigments. Appl. Microbiol. Biotechnol. 96, 14211440.

Hsu, Y.W., Hsu, L.C., Liang, Y.H., Kuo, Y. H., Pan, T.M. (2011) New bioactive orange pigments with yellow fluorescence from Monascus fermented dioscorea. J. Agric Food Chem. 59, 4512-4518.

Jeon, C. P., Lee, J. B., Choi, S. Y., Shin, J. W., Lee, O. S., Choi, C. S., Rhee, C. H. and Kwon, G. S. (2006) Optimal culture condition for production of watersoluble red pigments by Monascus purpureus. J. Korean Soc. Food Sci. Nutr., 35 (4), 493-498.

Ji, H., Jiang, D. and Cao, L. (2012) Optimization of fermentation parameters on T-DNA inserted M. purpureus mutant MT24 with high pigment production capacity. Res. J. Biotechnol., 7, 9-14.

Joshi, V.K., Attri, D., Bala, A. and Bhushan, S. (2003) Microbial pigments. Indian J Biotechnol., 2, 362-
369.

Juzlova, P., Martincova, I. and Lozinski, J. (1994) Ethanol as substrate for pigment production by the fungus Monascus. Enzyme Microbial. Technol., 16, 996-1001.

Juzlova, P., Martinkova, L. and Kren, V. (1996) Secondary metabolites of the fungus Monascus: A review. J. Indust. Microbial. 16, 163-170.

Kim, C., Jung, H., Kim, Y.O. and Shin, C.S. (2006) Antimicrobial activities of amino acid derivated of Monascus pigments. FEMS Microbiol. Lett. 264, $117-124$.

Kraboun, K., Jittrepotch, N., Kongbankerd, T. and Rojsuntornkitti, K. (2009) Effect of Monascus pigments from broken rice on inhibition of rancidity in Chinese sausage. Proceedings of $47^{\text {th }}$ Kasetsart University Annual Conference: AgroIndustry, Kasetsart University, Bangkok, Thailand. pp. 365-373.

Lee, B.H.; Hsu, W.H.; Liao, T.H. and Pan, T.M. (2011) The Monascus metabolite monascin against TNFalpha-induced insulin resistance via suppressing PPAR-gamma phosphorylation in $\mathrm{C} 2 \mathrm{C} 12$ myotubes. Food Chem. Toxicol., 49 (10), 2609-17.

Lee, B.K., Park, N.H., Piao, H.Y. and Chung, W.J. (2001) Production of red pigments by Monascus purpureus in submerged culture. Biotechnol Bioprocess Eng. 6,341-346.

Lee, Y.K., Chen, D.C, Chauvatcharin, S., Seki, T. and Yoshida, T. (1995) Production of Monascus pigments by a solid-liquid state culture method. $J$. Ferment. Bioeng., 79, 516-518.

Lin, C.F. and Iizuka, H. (1982) Production of extracellular pigment by a mutant of Monascus kaoliang sp. nov. Appl. Microbiol. Biotechnol., 43, 671-676.

Lin, T.F. (1991) Studies on the formation of Monascus red pigments. PhD Thesis, Massachusetts Inst. Technol., M.A., USA.

Lin, T.F. and Demain, A.L. (1991) Effect of nutrition of Monascus sp. on formation of red pigments. Appl Microbiol Biotechnol., 36, 70-75.

Lin, T.F., Yakushijin, K., Büchi, G.H. and Demain, A.L. (1992) Formation of water-soluble Monascus red pigments by biological and semi-synthetic processes. Journal of Industrial Microb., 9, 173179. 
Mal'a, P., Baranová, M., Marcinčáková, D. and Nagy, J. (2010) Organoleptic Evaluation of Poultry Meat Products with Wheat Protein Seitan, Colored by Microbial Natural Pigment. Assam University Journal of Science \& Technology: Biological and Environmental Sciences, 5 (I), 1-5.

Mamucod, H.F. and Dizon, E.I. (2014) Potential of biopigments from Monascus purpureus Went as natural food colorant for Philippine native sausage (Longganisa). Int P Chem Bio Environ Eng., 71, 72-6.

Manchand, P.S. and Whalley, W.B. (1973) Isolation and structure of ankaflavin: a new pigment from Monascus anka. Phytochemictry 12, 2531-2532.

Martlnková, L., Juzlová, P. and Vesely, D. (1995) Biological activity of polyketide pigments produced by the fungus Monascus. J. Appl Microbiol., 79, 609-616.

Mekhael, R. and Yousif, S.Y. (2009) The role of red pigment produced by Serratia marcescens as antibacterial and plasmid curing agent. $J$ Duhok Univ. 12 (1), 268-274.

Minoru, Y., Shigeru, Y., Koji, M. and Yoshio, H. (1975) Production of Monascus Pigment in a Submerged Cultures, Agr. Biol. Chem., 39 (9), 1789 -1795.

Miyake, T., Sakai, S. and Ohno, S. (1982) Process for the production of Monascus-pigment. UK Patent, 2102024

Mostafa, M.E. and Abbady, Ma, (2014) Secondary metabolites and Bioactivity of the Monascus pigments review article. Glob. J. Biotechnol. Biochem. 9 (1), 01-13.

Orozco, S.F.B. and Kilikian, B.V. (2008) Effect of pH on citrinin and red pigments production by Monascus purpureus CCT 3802. World J. Microbial Biotech. 24, 263-268.

Padmavathi, T. and Prabhudessai, T. (2013) A solid liquid state culture method to stimulate Monascus pigments by intervention of different substrates Int Res. J. Biological Sci. 2 (10), 22-29.

Panitz, C.; Frost, P. and Kunz, B. (1991) Pigment- und Biomassebildung von Monascus purpureus in synthetischen Medien. BioEng, 7, 72-75.

Park. C.D., Jung, H. J. and Yu, T.S. (2005) Optimization of pigment production of Monascus purpureus $\mathrm{P}-57$ in liquid culture. Korean J. Biol. BioEng, 20, 66-70.

Patakova, P. (2013) Monascus secondary metabolites: production and biological activity, Journal of IndustrialMicrobiology and Biotechnology, 40 (2), 169-181.

Patakova, P., Branska, B. and Patrovsky, M. (2015) Monascus Secondary Metabolites, Springer International Publishing, 1-31.

Pattanagul, P., Pinthong, R. and Phianmongkhol, A. (2007) Review of Angkak Production (Monascus purpureus). Chiang Mai J. Sci., 34 (3), 319-328.

Pirt, S.J. (1985) Principles of microbe and cell cultivation, Blackwell Sci. Public., London.

Pyo, Y.H. and Lee, T. (2007) The potential antioxidant capacity and angiotensin I-coverting enzyme inhibitory activity of Monascus-fermented soybean extract: evaluation of Monacus-fermented soybean extract as multifunctional food additives. J. Food Sci. 72, 218-223.

Rashmi, D. and Padmavathi, T. (2012) Comparative study of Monascus sanguineus and Monascus purpureus as potential sources for red pigment production, Int. J. Pharm Bio Sci., 3 (4),885-895.

Rashmi, D. and Padmavathi, T. (2013) Exploring Monascus sanguineus as a Potential Natural Source for Pigment Production, Int. Res. J. Biological Sci., 2 (5), 59-67.

Reitmeier, C.A. and Nonnecke, G.R. (1991) Objective and sensory evaluation of fresh fruit of day neutral strawberry cultivars. J. Hor. Sci. 26, 843-845.

Santos-Ebinuma, V.C., Teixeira, M.F.S. and Pessoa, Jr. A. (2013b) Submerged culture conditions for the production of alternative natural colorants by a newly isolated Penicillium purpurogenum DPUA 1275. J. MicrobialBiotech, 23, 802-810.

Shi, Y.C. and Pan, T.M. (2011) Beneficial effect of Monascus purpureus NTU 568-fermented product: a review. Appl Microbial Biotechnol. 90, 12071217.

Singgih, W. and Julianti E. (2015) Food colorant from microorganisms. M.-T. Liong (Ed.) Beneficial Microorganism in Food and Nutraceuticals, Microbiology Monographs 27.

Su, N-W., Lin, Y-L., Lee, M-H. and Ho, C-Y. (2005) Ankaflavin from Monascus-fermented red rice exhibits selective cytotoxic effect and induces cell death on Hep G2 cells. J. Agric. Food. Chem., 53(6), 1949-54.

Suh, S-K., Rhee, C-H. and Woo, C-J. (2004) Studies

Egypt. J. Food. 47, No. 2 (2019) 
on the optimal culture condition for production for production of red pigments by Monascus rubber on liquid culture. Korean J. Food Preserv, 11(1), 111 $-116$.

Sumathy, B., Carlos, R.S. and Pandey, A. (2007) Effect of Stress on Growth, Pigment Production and Morphology of Monascus sp. in Solid Cultures, $J$. Basic Microbiol., 47, 118-126.

Tseng, Y., Yang, J., Chang, H., Lee, Y. and Mau, J. (2006) Antioxidant properties of methanolic extract from monascal adlay. Food Chem. 97 (3), 375-381.

Tseng, Y.Y., Chen, M.T. and Lin, C.F. (2000) Growth, pigment production and protease activity of Monascus purpureus as affected by salt, sodium nitrite, polyphosphate and various sugars. $J$. Applied Microbial. 88, 31-37.

Vendruscolo, F., Bühler, R.M., Carvalho, J.C., Oliveira, D., Moritz, D.E., Schmidell, W. and Ninow, J.L. (2015) Monascus: a reality on the production and application of microbial pigments. Appl. Biochem. Biotechnol.http://dx.doi.org/10.1007/s12100151880-z.

Verma, G.; Nigam, P.; Singh, D. and Chaudhary, K. (2000) Bioconversion of starch to ethanol in a single-step process by coculture of amylolytic yeasts and Saccharomyces serevisiae 21. Bioresource Technol., 72, 261- 266.
Vidyalakshmi, R., Paranthaman, R., Murugesh, S. and Singaravadivel, K. (2009) Stimulation of Monascus pigments by intervention of different nitrogen sources. Global J. of Biotechnol. and Biochem. 4, 25-28.

Wang, E. X. and J. Zhao. (2008) Application of sensory evaluation in meats. Meat Res. 9, 78-82. (In Chinese)

Yang, C., Wu, X., Chen, B., Deng, S.S., Chen, Z.E., Huang, Y.Y. and Jin, S.S. (2016) Comparative analysis of genetic polymorphisms among Monascus strains by ISSR and RAPD markers, Journal of the Science of Food and Agriculture, 97 (2), 636-640.

Yang, J.H., Tseng, Y.H., Lee, Y.L.and Mau, J.L. (2006) Antioxidant properties of methanolic extracts from monascar rice. LWT 39, 740-747.

Yoshimura, M., Yamanaka, S., Mitsugi, K. and Hirose, Y. (1975) Production of Monascus pigment in a submerged culture. Agric. Biol. Chem., 39, 17891795 .

Zeng Huawei, Qiao Jie, Zeng Xin, Xu Dayong, Xiong Minghua, Li Feng, Sun Jianfan, Jiang Xuan, Dai Chuanyun, (2018) Optimization of submerged and solid state culture conditions for Monascus pigment production and characterization of its composition and antioxidant activity, Pigment \& Resin Technology, https://doi.org/10.1108/PRT-052018-0046.
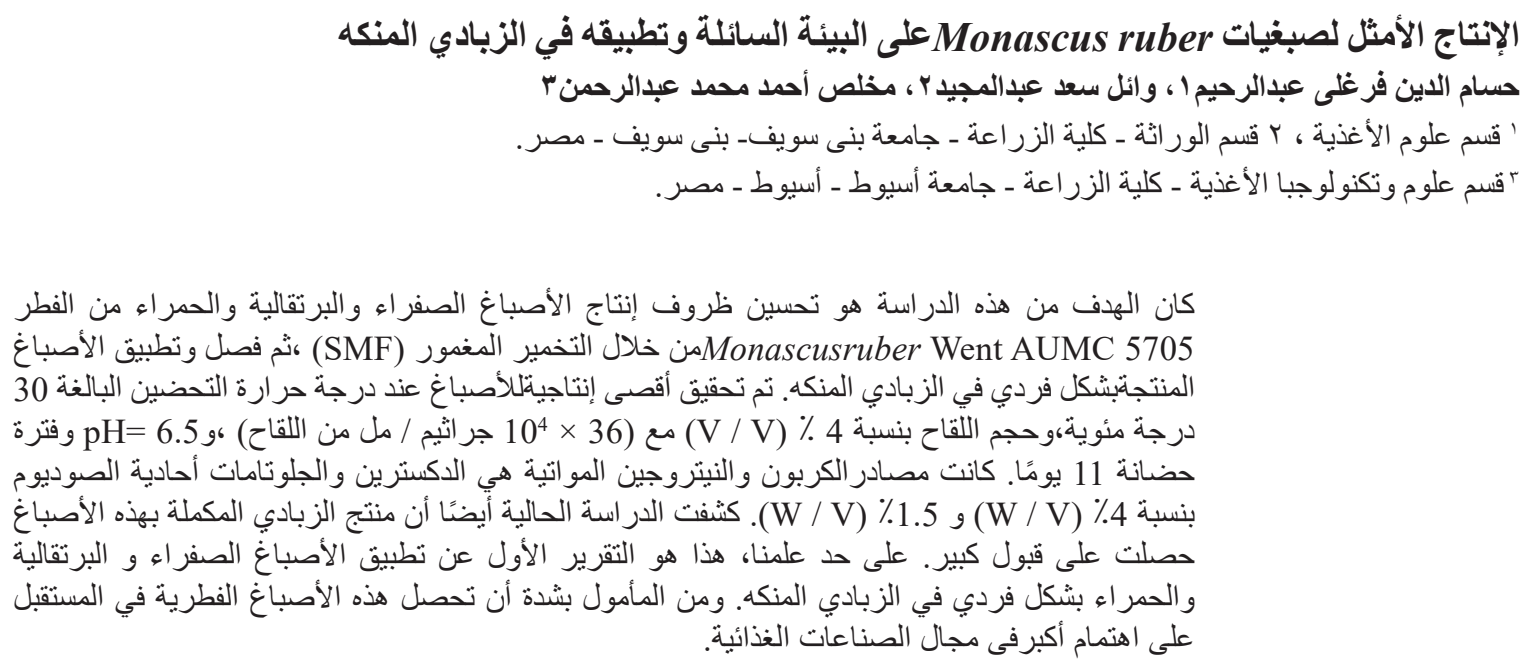